\title{
Short-term impacts of enhanced Greenland freshwater fluxes in an eddy-permitting ocean model
}

\author{
R. Marsh ${ }^{1}$, D. Desbruyères ${ }^{2}$, J. L. Bamber ${ }^{3}$, B. A. de Cuevas' ${ }^{4}$, A. C. Coward ${ }^{4}$, and Y. Aksenov ${ }^{4}$ \\ ${ }^{1}$ School of Ocean and Earth Science, University of Southampton, European Way, Southampton, Hampshire SO14 3ZH, UK \\ ${ }^{2}$ Lab. de Physique des Océans, Univ. de Bretagne Occidentale, 6 av. Le Gorgeu CS 93837, 29238 Brest Cedex 3, France \\ ${ }^{3}$ Bristol Glaciology Centre, School of Geographical Sciences, University of Bristol, UK \\ ${ }^{4}$ National Oceanography Centre, European Way, Southampton, Hampshire SO14 3ZH, UK
}

Received: 11 November 2009 - Published in Ocean Sci. Discuss.: 27 November 2009

Revised: 26 May 2010 - Accepted: 8 July 2010 - Published: 23 July 2010

\begin{abstract}
In a sensitivity experiment, an eddy-permitting ocean general circulation model is forced with realistic freshwater fluxes from the Greenland Ice Sheet, averaged for the period 1991-2000. The fluxes are obtained with a mass balance model for the ice sheet, forced with the ERA-40 reanalysis dataset. The freshwater flux is distributed around Greenland as an additional term in prescribed runoff, representing seasonal melting of the ice sheet and a fixed year-round iceberg calving flux, for 8.5 model years. By adding Greenland freshwater fluxes with realistic geographical distribution and seasonality, the experiment is designed to investigate the oceanic response to a sudden and spatially/temporally uniform amplification of ice sheet melting and discharge, rather than localized or gradual changes in freshwater flux. The impacts on regional hydrography and circulation are investigated by comparing the sensitivity experiment to a control experiment, without additional fluxes. By the end of the sensitivity experiment, the majority of additional fresh water has accumulated in Baffin Bay, and only a small fraction has reached the interior of the Labrador Sea, where winter mixed layer depth is sensitive to small changes in salinity. As a consequence, the impact on large-scale circulation is very slight. An indirect impact of strong freshening off the west coast of Greenland is a small anti-cyclonic component to the circulation around Greenland, which opposes the wind-driven cyclonic circulation and reduces net southward flow through the Canadian Archipelago by $\sim 10 \%$. Implications for the post-2000 acceleration of Greenland mass loss are discussed.
\end{abstract}

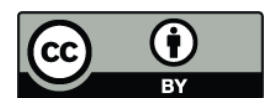

Correspondence to: R. Marsh (rma@noc.soton.ac.uk)

\section{Introduction}

The Greenland Ice Sheet (GrIS) appears to have been losing mass since the 1990s (van den Broeke et al., 2009). Over each annual cycle, this net mass loss comprises roughly equal amounts of surface runoff and solid ice fluxes across the grounding lines of ocean-terminating glaciers. Surface mass balance models of the GrIS provide the detailed pattern of runoff to the ocean (e.g. Fettweis, 2007). These data can be combined with estimates of grounding line fluxes from satellite observations of velocity (Rignot and Kanagaratnam, 2006) to produce the spatial distribution of freshwater fluxes (FWF), which can be prescribed as forcing in an ocean circulation model. Such an experiment has been undertaken using rough estimates of FWF from Greenland and Antarctica in a global model with $1^{\circ}$ resolution (Stammer, 2008). That study suggested that advection of freshwater from the North Atlantic takes decades and is modulated by Rossby waves. As a result, there is a regional accumulation of freshwater that results in a substantial sea surface height (SSH) anomaly. The model resolution in that study was, however, insufficient to permit eddies, and model boundary currents are broader than in reality.

Determining the precise fate of FWF from Greenland requires ideally an eddy-resolving model, as much of the flux may be entrained in the narrow boundary current that flows south along the east coast as the East Greenland Coastal Current (Bacon et al., 2002) and north along the west coast of Greenland, before returning south along the Canadian Arctic coast. If this is the case, then models that poorly resolve boundary currents may not be suitable for studying the impact of Greenland melt water on the North Atlantic. To go some way to address this issue we employ

Published by Copernicus Publications on behalf of the European Geosciences Union. 

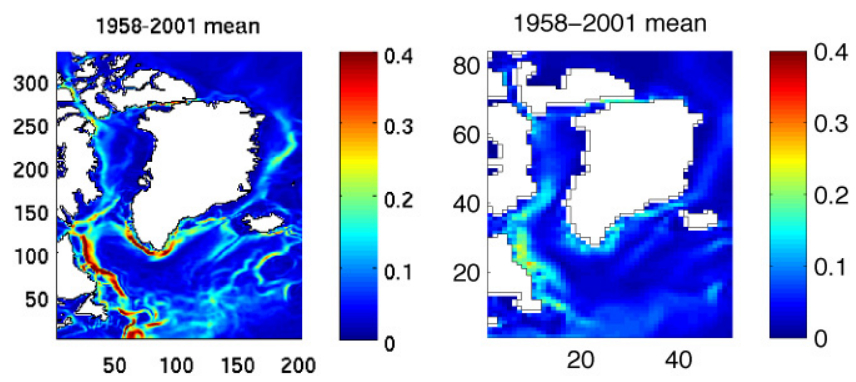

Fig. 1. Surface current speed $\left(\mathrm{m} \mathrm{s}^{-1}\right)$ averged over 1958-2001 in control experiments with NEMO at resolutions of $0.25^{\circ}$ and $1^{\circ}$ (left and right panels respectively).

an eddy-permitting model to explore the short-term advection and mixing of FWF from the GrIS. In comparing a meltwater-forced simulation to a control simulation, we effectively investigate the short-term impact of a sudden, sustained and substantial increase of GrIS meltwater input to the adjacent oceans. Investigation of this first-order impact is motivated by the recent acceleration in GrIS mass loss (Velicogna, 2009), and the likelihood that this melting will be sustained.

The paper is organized as follows. By way of experimental design, we outline the ocean model, and the method by which the freshwater fluxes are obtained and prescribed in the model. In the results section, we focus on the development of a fresh anomaly around Greenland, the impacts on regional hydrography, and associated changes in ocean circulation around Greenland. In the discussion, we draw some basic conclusions about the likely pattern of freshening that may soon be detected around Greenland. Caveats inherent in the present experimental design are also considered.

\section{Experimental design}

\subsection{Ocean model}

For the present experiments, we use an ocean model based on NEMO, the Nucleus for European Modelling of the Ocean. NEMO is a European modelling community effort to advance ocean modelling for ocean climate research and operational oceanography through a state-of-art common flexible modelling framework. The core of the framework contains the ocean model OPA v9.0 and sea ice model LIM3. The LIM3 model is based on Elastic-Viscous-Plastic ice dynamics, has energy-conserving thermodynamics, a multicategory representation of sea ice thickness, and an explicit description of the salt evolution within sea ice. The last of these is essential in order to simulate sea ice evolution and sea ice-ocean coupling correctly (Vancoppenolle et al., 2009). Following Campin et al. (2008), we use the embedded sea ice scheme with a re-scaled vertical coordinate for
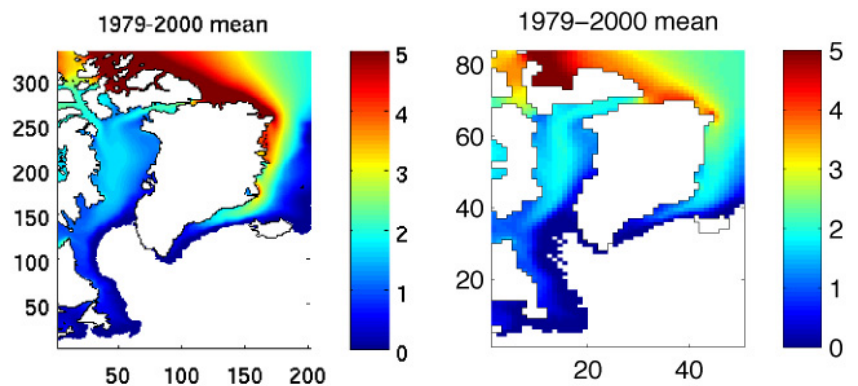

Fig. 2. March sea ice thickness (m) averaged over 1979-2000 in control experiments with NEMO at resolutions of $0.25^{\circ}$ and $1^{\circ}$ (left and right panels respectively).

the sea ice-ocean coupling, for more accurate simulation of the mass and salt exchange between sea ice and ocean.

The NOCS version of NEMO used here is a global implementation at $1 / 4^{\circ}$ resolution (ORCA025). Due to the use of a curvilinear grid, ORCA025 has horizontal resolution of around $16 \mathrm{~km}$ in the vicinity of Greenland and the Labrador Sea. The model is forced by the DFS3 set of surface fluxes, developed through the DRAKKAR consortium to drive the ORCA025-NEMO system and maintain a realistic overturning circulation in the Atlantic. Using this configuration of NEMO, a series of control experiments have been carried out for the period 1958-2001 (Grist et al., 2010).

At eddy-permitting resolution, the subpolar gyre is represented with substantially more realism than in lower resolution studies. To illustrate the extent of improvement in surface flows, Fig. 1 shows the surface current speed averaged over 1958-2001 in control experiments with NEMO at resolutions of $0.25^{\circ}$ and $1^{\circ}$ (left and right panels respectively). The two control experiments are otherwise identically forced. The mean circulation in the eddy-permitting case is characterized by narrow (100-200 km width) boundary currents around the subpolar gyre, with maximum speeds of around $40 \mathrm{~cm} \mathrm{~s}^{-1}$ off Labrador and south Greenland. At coarser resolution, the corresponding maximum speed is around $15 \mathrm{~cm} \mathrm{~s}^{-1}$. The eddy-permitting simulation also presents a more realistic Arctic outflow both east and west of Greenland. In this simulation, the East Greenland Current and the Baffin Island Current are more coherent and stronger, compared to the coarse resolution experiment (Fig. 1). The higher speeds in the eddy-permitting simulation are in closer agreement with in situ observations from moored current meters (Schauer et al., 2008; Holliday et al., 2009; Curry et al., 2010) or surface drifters (e.g., Cuny et al. 2002).

The NOCS configuration of NEMO also has an increased number of vertical levels, from 46 levels in the reference version to 64 levels, with a resolution of $6 \mathrm{~m}$ near the surface. This improves the simulation of sea ice and upper ocean dynamics. The further importance of higher horizontal resolution for sea ice is illustrated in Fig. 2, which shows March 

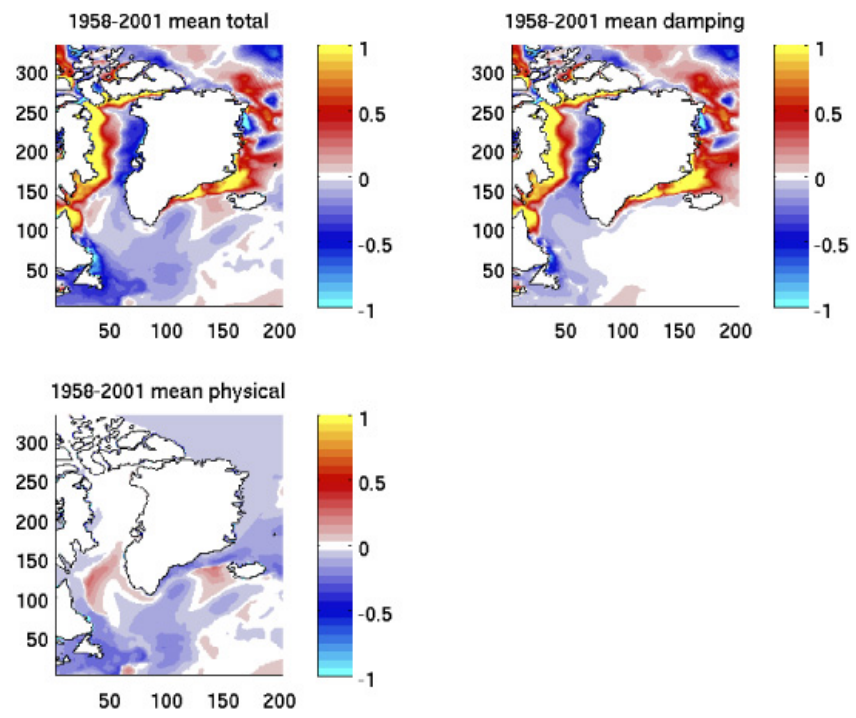

Fig. 3. Total surface water flux (positive upward, units $10^{-4} \mathrm{~kg} \mathrm{~m}^{-2} \mathrm{~s}^{-1}$ ), damping surface water flux, and physical surface water flux (precipation plus runoff plus net ice-ocean flux minus runoff), averaged for 1958-2001 in the control simulation.

sea ice thickness for the two control simulations, averaged over 1979-2000 (a time period chosen for comparison with satellite-era observations). At the higher resolution, there is a clear improvement in sea ice thickness north of Greenland and the Canadian Archipelago and in the Greenland Sea, compared to the limited sea ice thickness observations (e.g., Melling, 2002). The implied sea ice extent around Greenland, in the Labrador Sea, and off the Grand Banks is also more realistic in the eddy-permitting simulation, by comparison with corresponding satellite observations (National Snow and Ice Data Center, 2010).

In the present study, additional GrIS freshwater fluxes are added from July 1993 onwards (to December 2001). The control and sensitivity experiments are directly compared, to identify the impact of GrIS fluxes on hydrography and circulation. In addition to freshwater forcing, it is necessary to relax model surface salinity towards observed sea surface salinity (monthly-mean climatological values), in order to maintain a realistic overturning circulation. For the ice-free ocean, the relaxation coefficient is equivalent to a freshwater flux of $0.033 \mathrm{~m} \mathrm{day}^{-1}$ per psu of salinity difference, and the associated relaxation timescale is 180 days. In the presence of ice, much stronger relaxation is necessary, with a coefficient of $0.167 \mathrm{~m} \mathrm{day}^{-1}$ per psu difference, and an associated relaxation timescale of just 12 days.

Figure 3 shows the total surface water flux (upper left panel), along with damping and physical components (upper right panel and lower panel respectively), all averaged for 1958-2001 in the eddy-permitting control simulation. With the sign convention of positive flux upward, negative values correspond to freshwater gain. This is consistent with an excess of precipitation over evaporation in the interior of the subpolar gyre, and net sea ice melt around the Grand Banks, but a notable feature in Fig. 3 is the dominance of the damping term around Greenland and at high latitudes generally. The strongly positive damping flux in the Canadian Archipelago and in the western part of Baffin Bay is due to the excessive outflow of fresh Arctic waters through the Canadian straits (cf., $2.5 \mathrm{~Sv}$ in the simulation and $1.8 \mathrm{~Sv}$ in observations, Melling et al., 2008). The strong negative damping, evident in the eastern part of Baffin Bay, is caused by the northward surface flow through eastern Davis Strait in the model being too saline compared to the observed (e.g., Curry et al., 2010). Overall though, the diagnosis of transports in the present simulation is very similar to that for a similar model implementation by Lique et al. (2009) and is in a reasonable agreement with estimates based on observations (Melling et al., 2008; Schauer et al., 2008; Curry et al., 2010), considering large uncertainties in the latter. The strong damping fluxes are clearly also due to the presence of sea ice for all or most of the year and the strong surface salinity relaxation under sea ice. Given this high latitude sensitivity, the surface salinity damping is expected to strongly oppose freshening attributed to the additional GrIS freshwater fluxes imposed in the sensitivity experiment.

\subsection{Climatological GrIS meltwater fluxes, 1991-2000}

Ice sheet model estimates of seasonal surface runoff were obtained by forcing a high-resolution $(5 \mathrm{~km})$ mass balance model of the GrIS with ERA-40 surface boundary conditions for 1991-2000 (Bougamont et al., 2005). Monthlymean melt-water fluxes were calculated for 1991-2000 and integrated downslope to produce surface runoff estimates at the ice margins. The solid ice fluxes were taken from published estimates derived from satellite velocity and ice thickness measurements, using the 1996 flux values (Rignot and Kanagaratnam, 2006). The total annual flux from the GrIS to the surrounding ocean, from this analysis, was $658 \mathrm{~km}^{3}$ compared with a mean accumulation over the ice sheet of $621 \mathrm{~km}^{3}$ for the same time period. The mass imbalance, of $37 \mathrm{~km}^{3}$ year $^{-1}$, is somewhat smaller than, but comparable in magnitude to, the estimate of the mass balance for 1996 from mass budget calculations (Rignot and Kanagaratnam, 2006). Due to strong relaxation of surface salinity in NEMO, the actual annual freshwater gain is considerably less than $658 \mathrm{~km}^{3}$ year ${ }^{-1}$, averaging around $100 \mathrm{~km}^{3}$ year over 1993-2001.

The fluxes at individual gridcells within the GrIS (Fig. 4) were averaged up to the NEMO resolution and re-located at the nearest ocean gridcell, around the coast of Greenland. The pattern of FWF around the coastline of Greenland is substantially different from prescriptions in previous model experiments (Saenko et al., 2007; Stammer, 2008), in which strong melting is located around southern and eastern Greenland, representative of recent and future net mass 


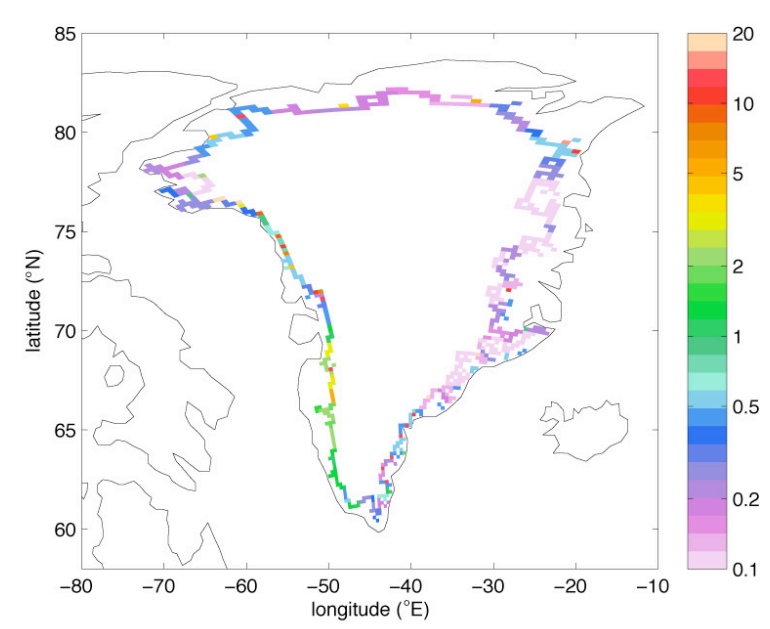

Fig. 4. Annual melt fluxes $\left(\mathrm{km}^{3}\right)$ predicted with an energy mass balance model of the Greenland Ice Sheet (averaged for 1991-99), as located on the ice sheet, prior to re-location to coastal gridcells of NEMO.

loss. In the present study, in contrast, the strongest (climatological) fluxes are located along the west coast, and fluxes are in general more equally distributed around all of Greenland. Figure 5 shows monthly and annual-mean total runoff from the Greenland coast for 1991-2000, revealing a strong seasonal cycle, with summer/autumn fluxes higher by a factor of $\sim 5$ compared to annual mean fluxes. While there is some interannual variability in summer melt rates, we use monthly mean fluxes in the present experiment. These fluxes are added to the climatological (control) runoff field, which provides only a first-order representation of the freshwater flux from Greenland. Figure 6 shows the seasonal cycles of GrIS runoff specified in each year of the control and sensitivity experiments. In the sensitivity experiment, the additional GrIS fluxes boost total runoff from Greenland by a factor ranging from $\sim 2$ (winter) to $\sim 4$ (summer). In addition to a change in amplitude of the seasonal cycle, the summer peak shifts from June to July with additional GrIS fluxes. There is no clear reason for this, although it may be that sparse Greenland runoff in the control simulation is biased to south Greenland, where melting starts earlier in the spring, whereas the more complete ice sheet model prediction additionally includes later-season melting further to the north.

\section{Results}

On the short timescale considered here, and under modest additional freshwater forcing, the impact on large-scale circulation (subpolar gyre, meridional overturning) is almost indiscernible. We therefore focus on the immediate impact of freshwater addition on hydrography and circulation near to Greenland.

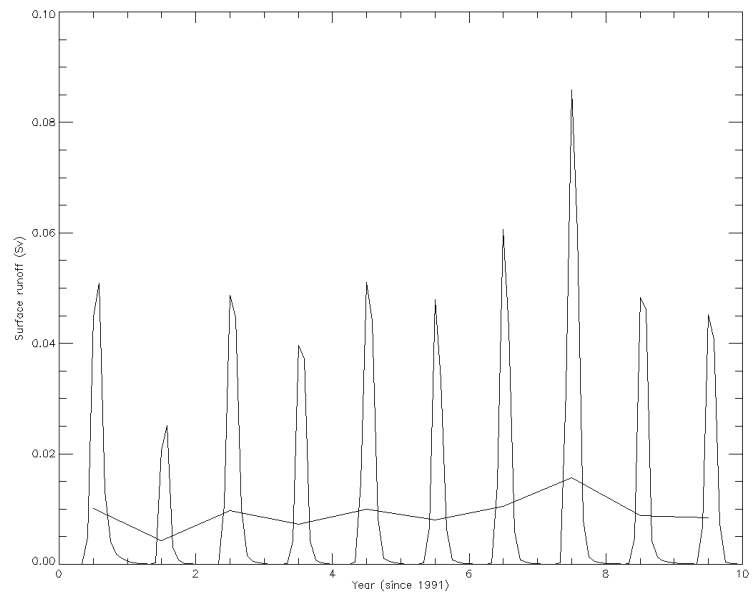

Fig. 5. Monthly and annual-mean surface runoff (Sv) from Greenland for 1991-99. This does not include the iceberg calving fluxes, which are assumed constant throughout the year. The iceberg flux is approximately equal in magnitude to the mean annual runoff in the simulation.

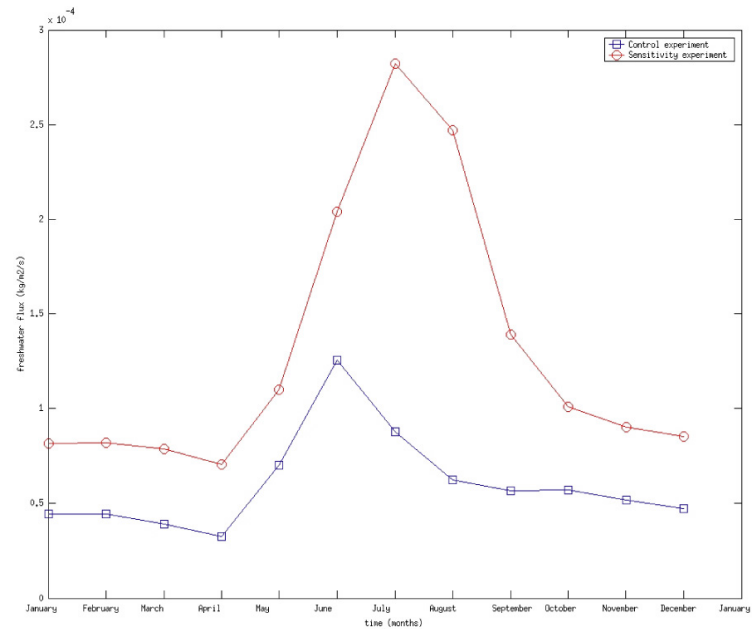

Fig. 6. Seasonal cycles of surface runoff (freshwater forcing, $\mathrm{kg} \mathrm{m}^{-2} \mathrm{~s}^{-1}$ ) along the Greenland coast, for the control experiment (blue curve) and the sensitivity experiment (red curve).

\subsection{Impacts on Hydrography and Mixed Layer Depth}

Over a timescale of 6 months, strong inputs of freshwater from southwest Greenland initially remain within 100 $200 \mathrm{~km}$ of the coast, with more extensive offshore anomalies appearing in surface salinity off the west coast, in the vicinity of Davis Strait, just north of Disko Bugt, and just south of Nares Strait (Fig. 7). Over the subsequent 8 years, more extensive annual-mean anomalies arise, notably to the west of Greenland (Fig. 8). Away from eddying regions, anomalies of sea surface temperature (SST) in the range $\pm 0.5^{\circ} \mathrm{C}$ are confined to the boundary currents, with cooling off southern Greenland and warming off Labrador (Fig. 9). The contour 

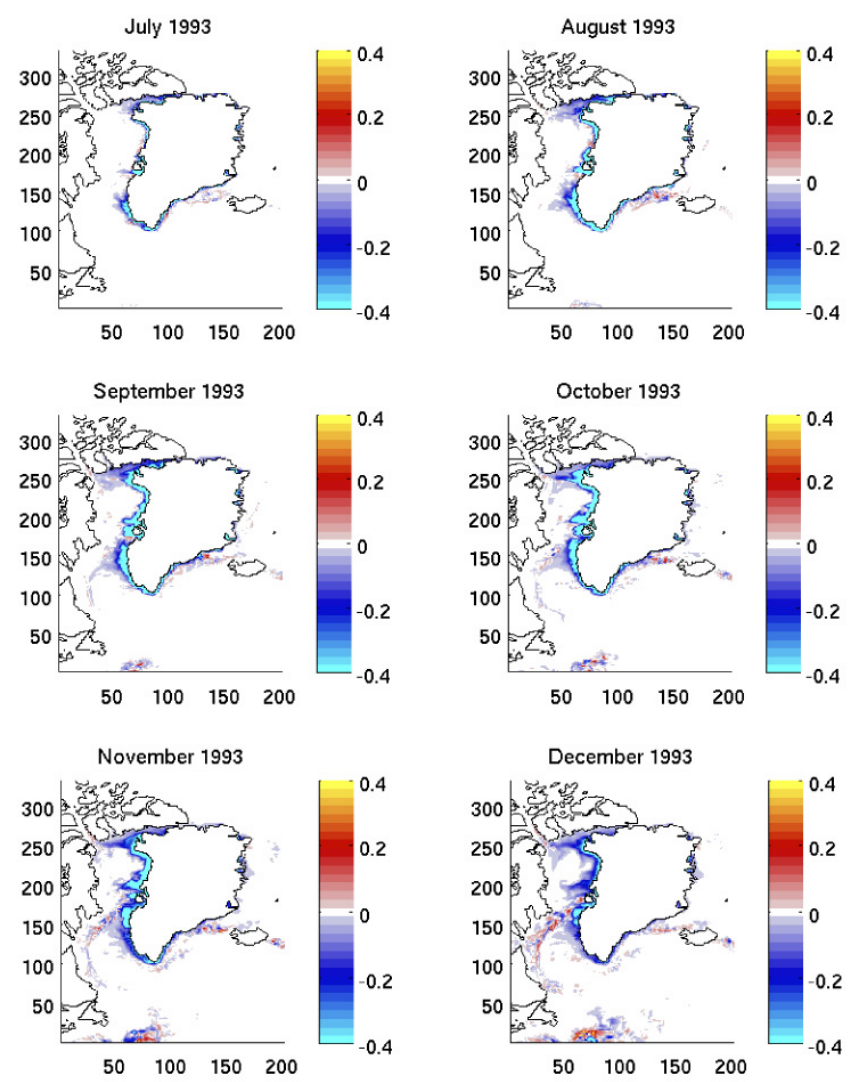

Fig. 7. Monthly anomalies of sea surface salinity (psu) around Greenland for the period July 1993-December 1993. These and subsequent anomalies are obtained as "sensitivity minus control" differences.

ranges in Figs. 8 and 9 are chosen such that the minimum (maximum) of salinity (temperature) change corresponds to the same reduction in surface density, indicating the relative influence on stratification of changes in surface salinity and temperature.

Strongest annual-mean warming off Labrador arises in 1997 and 1998, and is coincident with locally increased surface salinity (cf., Figs. 8 and 9). The changes in salinity are not explained by anomalies in surface freshwater flux anomalies (typically negligible in this vicinity - see below) or gyre-scale horizontal freshwater transport. Surface warming (cooling) and salinity increase (decrease) are more likely associated with local anomalous increases (decreases) in winter mixed layer depth (see below), which enhances (suppresses) upward mixing of the relatively warm and saline water that lies immediately beneath the cold, fresh surface layer in the western Labrador Sea (see Fig. 8 in Pickart et al., 2002). Substantial localized changes in mixed layer depth (in the sensitivity experiment) could thus act as a source of more widespread surface temperature and salinity anomalies, as evident around the western rim of the Labrador Sea in Figs. 8 and 9. Large positive and negative anomalies of salinity and tempertaure also arise in the inter-gyre zone, due to
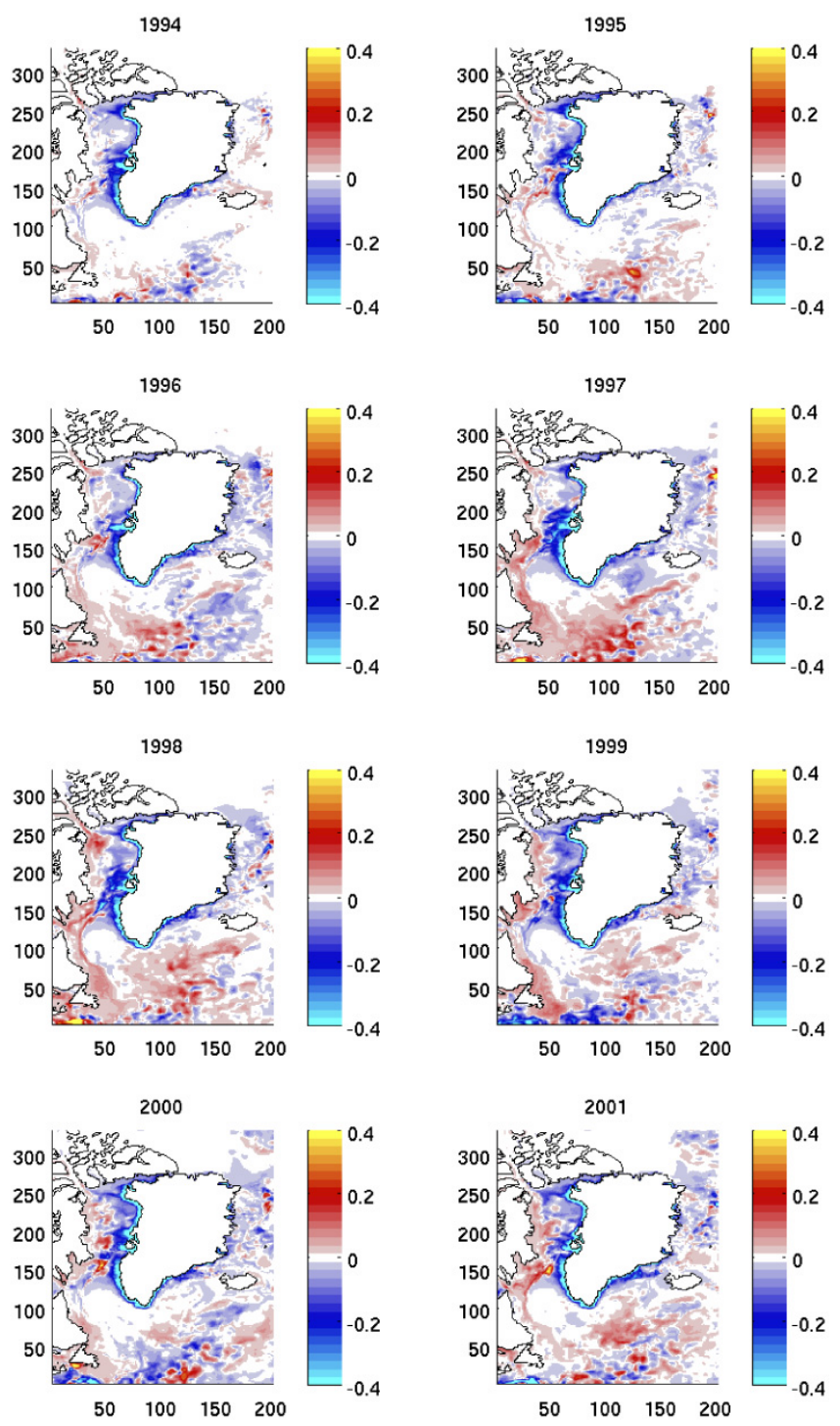

Fig. 8. Annual mean surface salinity anomalies (psu) for the period 1994-2001.

remote disturbance of the strongly-eddying North Atlantic Current, akin to the "butterfly effect" describing the sensitivity of weather forecasts to small perturbations of remote initial conditions.

Sub-surface salinity anomalies develop and spread both horizontally and vertically over the sensitivity experiment, but strong anomalies (exceeding $\pm 0.2 \mathrm{psu}$ ) are confined to the upper $200 \mathrm{~m}$. Figure 10 illustrates the evolution of salinity anomalies at $106 \mathrm{~m}$, a depth level representative of this freshening layer. The pattern is dominated by the development of negative anomalies in Baffin Bay, where relatively weak circulation (see Fig. 1) and a degree of recirculation is presumed to increase the residence time for enhanced GrIS runoff. The development of substantial salinity anomalies in the Arctic, off the north coast of Greenland, is less obviously explained, as neither runoff (see Fig. 4) nor damping fluxes 

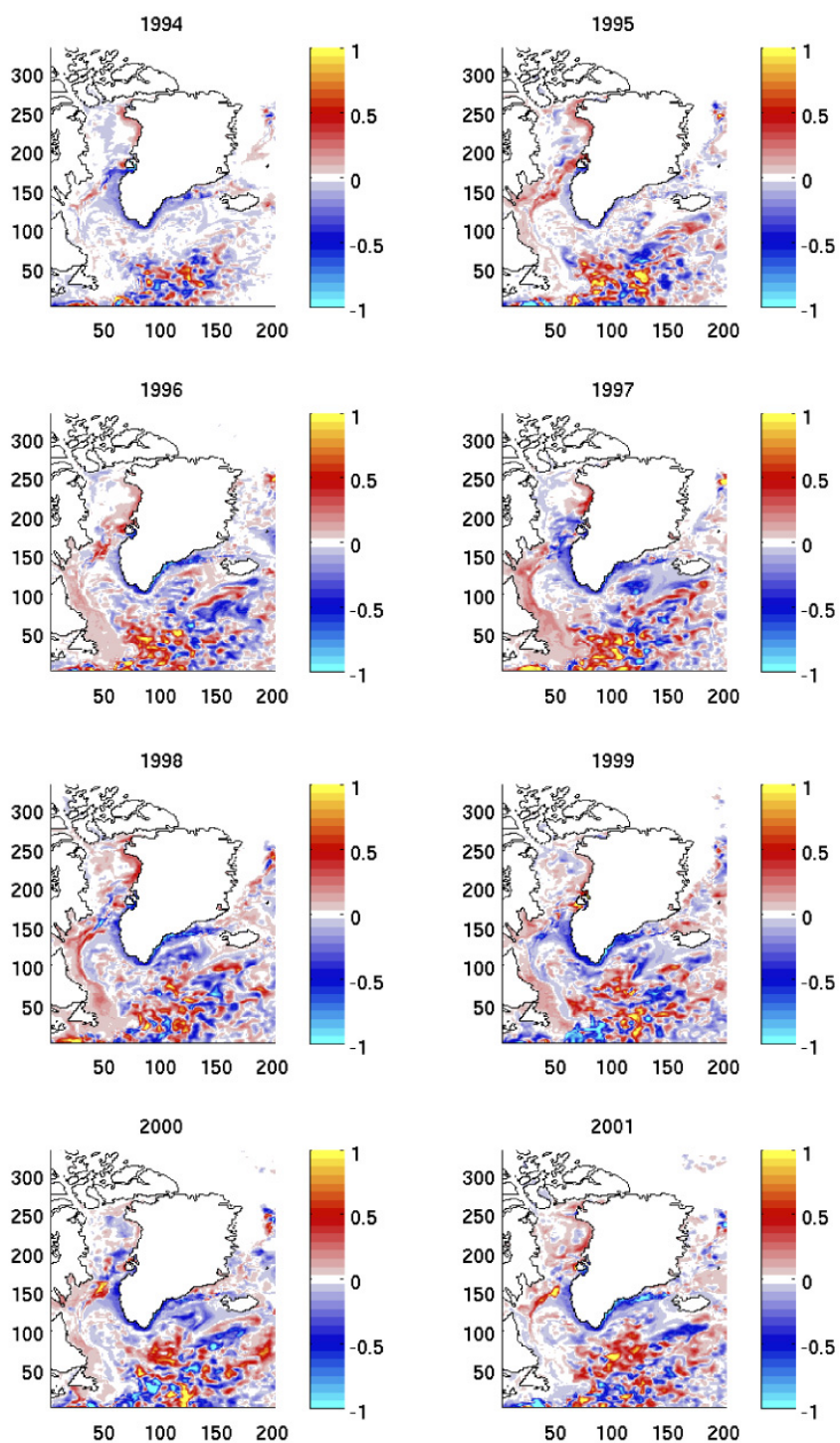

$50 \quad 100 \quad 150 \quad 200$
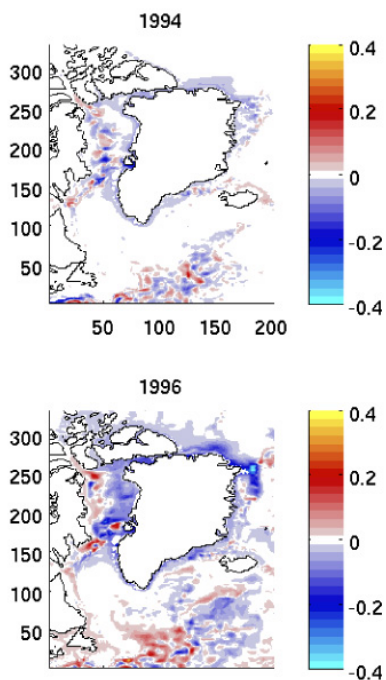

$\begin{array}{llll}50 & 100 & 150 & 200\end{array}$

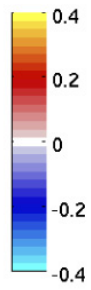

1998
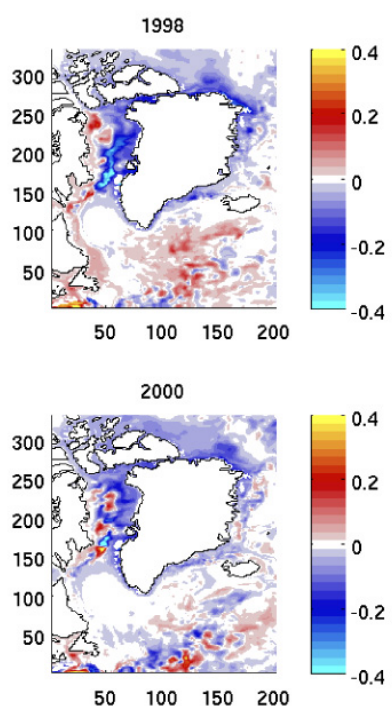
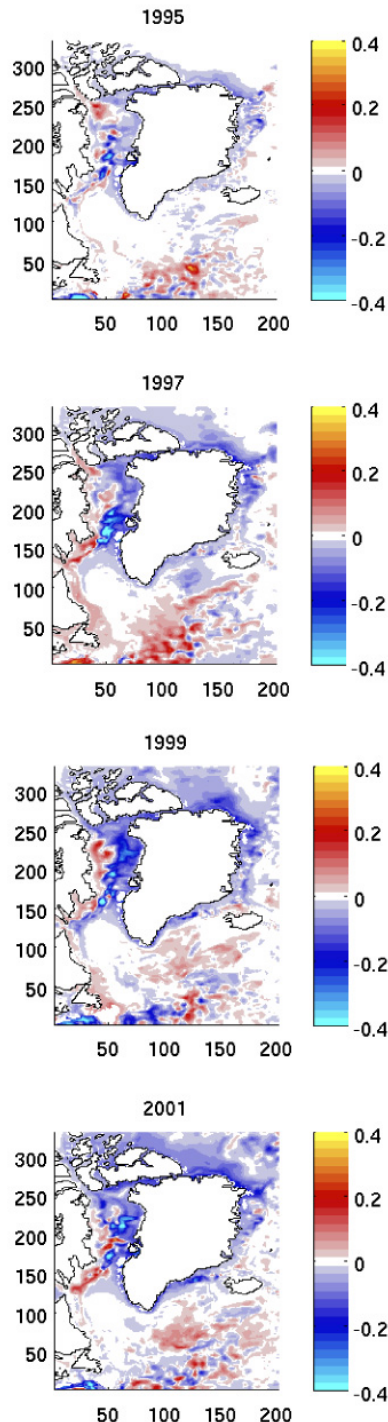

Fig. 10. Annual mean $106 \mathrm{~m}$ salinity anomalies (psu) for the period 1994-2001.

period 1994-2001.

(see Sect. 3.2) are locally enhanced. This fresh signal is due to northward advection of the additional freshwater fluxed onto the northeast Greenland shelf (see Fig. 8), by a narrow coastal current with velocities up to $10-15 \mathrm{~cm} \mathrm{~s}^{-1}$. This current is persistently seen in observations (Bourke et al. 1987; Budéus et al., 1997; Rabe et al., 2009), and is evident in the present NEMO simulation (not shown).

End-of-winter (March) mixed layer depth (MLD) in the Labrador Sea is rather sensitive to the additional melt water, deepening and shoaling by more than $500 \mathrm{~m}$ in some locations (Fig. 11), although these large anomalies are associated with deep mixed layers in the same locations (Fig. 12). Some areas of anomalous deepening persist throughout (e.g., at the northern rim of the Labrador Sea) and anomalous shoaling adjacent to most of the Labrador Current is persistent after

1997. Elsewhere, there is considerable spatial and interannual variability. In spite of these substantial MLD changes, there is little discernible influence on the meridional overturning circulation (not shown).

\subsection{Changes in Freshwater and Heat Content, Sea Level and Regional Circulation}

We first consider changes in surface fluxes and full-depth integral quantities, between early and later stages of the experiment, in 1995 and 2001 respectively. Noting the dominant influence of surface salinity relaxation in the vicinity of sea ice, we examine the two components of surface freshwater flux, as shown for the control experiment in Fig. 3. Using the same legend as in Fig. 3, Fig. 13 shows the differences (sensitivity minus control) in physical surface water flux (upper panels), 

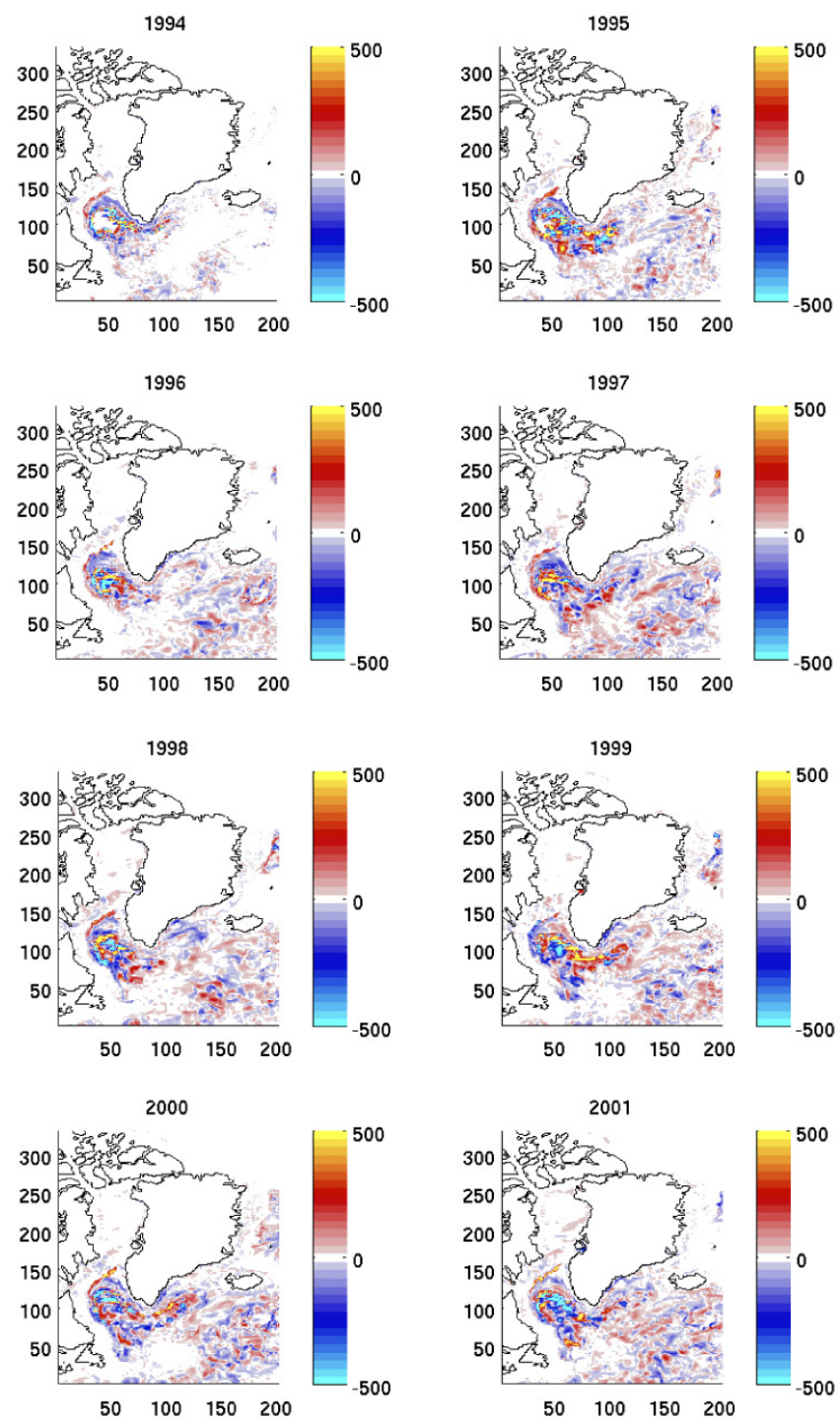

Fig. 11. March mixed layer depth anomalies (m) for the period 1994-2001.

and the surface damping term (lower panels), for 1995 and 2001. Away from the coastal gridboxes (where additional runoff is prescribed, indiscernible in Fig. 13), changes in the physical surface water flux can only arise through changes in sea surface temperature that lead to anomalies in evaporation rate. This component of the surface water flux is little altered. As expected though, the damping flux strengthens positively as the sensitivity experiment progresses, in Baffin Bay in particular, in proportion to the ongoing surface freshening (see Fig. 8). Based on a freshwater budget for the region shown in Fig. 13, the extra Greenland freshwater flux is effectively reduced by $\sim 85 \%$, although this reduction fluctuates considerably from month to month.

In spite of the strong surface damping, sub-surface freshening is substantial. While the sub-surface spreading of a fresh anomaly is largely restricted to the upper $200 \mathrm{~m}$, fresh- water content increases across the region over 1995-2001, evident as laterally spreading negative salt content anomalies (Fig. 14a). Patterns of salt content anomaly are similar to salinity anomaly at $106 \mathrm{~m}$ (see Fig. 10). By 2001, the majority of additional freshwater added over 1993-2001 has accumulated in Baffin Bay, with less prominent anomalies off the southeast coast of Greenland and in the Arctic Ocean adjacent to northern Greenland. Although an anomalous fresh signal can be traced along the narrow boundary current of the Labrador Sea, relatively little additional freshwater reaches the interior of the subpolar gyre, where only small negative anomalies develop by 2001. Corresponding heat content anomalies (Fig. 14b) indicate relatively smaller indirect impacts on temperature throughout the water column, notably in Baffin Bay, where salt content anomalies can be expected to dominate local density changes. To monitor changes in gyre-scale circulation that may influence freshwater and heat content in the Labrador Sea, we estimate transports across the repeat hydrographic section AR7W, between Cape Farewell and Labrador. In the sensitivity experiment, we identify negligible change in heat and salt transport across AR7W (not shown).

As a consequence of freshwater gain, depth-averaged density is reduced, the water column expands, and sea surface height (SSH) increases sterically. The pattern of annual-mean SSH differences between the two experiments (Fig. 14c) confirms that SSH increases around Greenland, by up to $5 \mathrm{~cm}$ in Baffin Bay, coincident to a large extent with increased freshwater content. The direct effect on sea level of a mass influx associated with runoff is not included in NEMO, so the SSH changes in Fig. 14c are the combination of steric effects (due to changes of both salinity and temperature) and changes in bottom pressure associated with the barotropic mode of circulation.

A notable feature in Fig. $14 \mathrm{c}$ is the $\sim 2 \mathrm{~cm}$ increase of coastal SSH around Greenland. This suggests a readjustment of the circulation around Greenland (Joyce and Proshutinsky, 2007) which is principally wind-driven, according to Godfrey's Island Rule (Godfrey, 1989). In the present case, strong additional runoff is expected to force a barotropic flow in direct response to the steric effect on sea level. SSH rise around Greenland is consistent with fast boundary wave propagation, observed throughout the World Ocean (Hughes and Meredith, 2006). An anomalous SSH signal originating principally in Baffin Bay would propagate around Greenland as a coastally-trapped wave with a phase speed of several m s${ }^{-1}$. With a coastline of $\sim 40000 \mathrm{~km}$ in length, boundary waves travelling at a speed of $5 \mathrm{~m} \mathrm{~s}^{-1}$ would complete a circuit of Greenland in around 90 days to establish a perturbed round-island flow. An additional barotropic response may be attributed to the Joint Effect of Baroclinicity And Relief (JEBAR, see Huthnance, 1984), depending on the extent to which freshening enhances stratification in the vicinity of topographic features such as the shelf break. Indeed, JEBAR has been invoked to explain 

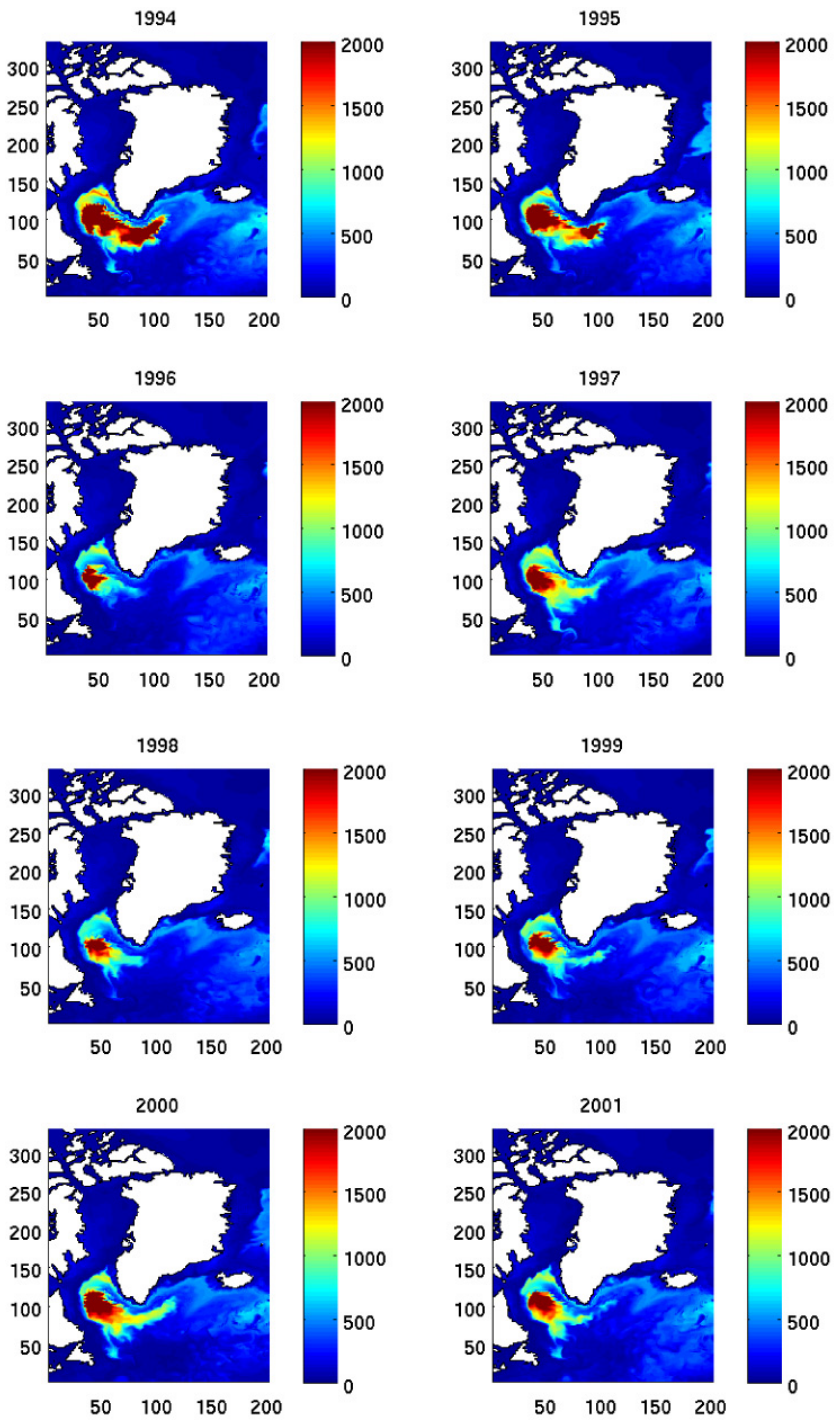

Fig. 12. March mixed layer depth (m) for the period 1994-2001 in the control experiment.

an observed seasonal cycle in the inshore Labrador Current (Lazier and Wright, 1993): shelf-break transport is observed to peak in October after reaching minimum values in MarchApril, a seasonal variation that has been associated with the flux of freshwater onto the shelf during summer. For an influx of freshwater onto the shelf around Greenland, JEBAR would correspondingly drive an anti-cyclonic flow around the island.

Initial evidence for such a perturbed flow is provided by a comparison of the southward transport west of Greenland in the two experiments (Fig. 15). When Greenland melting is included, net southward transport in Davis Strait (capturing nearly all of the west Greenland flow) is reduced by around $10 \%$ (e.g., from $2.45 \mathrm{~Sv}$ to $2.22 \mathrm{~Sv}$ in 2001). Based on a simple geostropic balance, reduction in transport of $0.23 \mathrm{~Sv}$ is consistent with the corresponding change in cross-shelf slope
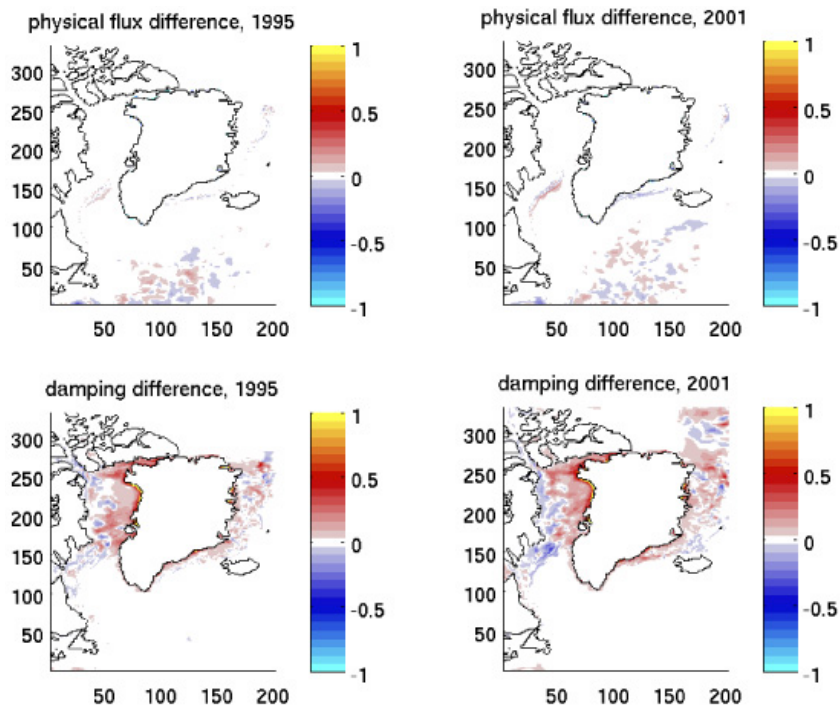

Fig. 13. Differences (sensitivity minus control) for 1995 and 2001 in the two components of annual-mean net upward water flux: physical surface water flux (upper panels), and the damping term (lower panels). Units are $10^{-4} \mathrm{~kg} \mathrm{~m}^{-2} \mathrm{~s}^{-1}$ ).

of sea surface height (Fig. 14c). At $70^{\circ} \mathrm{N}$, an anomalous slope (up towards the coast) of $2 \mathrm{~cm}$ across a shelf of typical width $200 \mathrm{~km}$ yields an anomalous depth-averaged velocity of $0.7 \mathrm{~cm} \mathrm{~s}^{-1}$ (anti-cyclonic around Greenland). For a typical shelf depth of $200 \mathrm{~m}$ (and width $200 \mathrm{~km}$ ), this correponds to a reduction in southward transport (west of Greenland) of $0.29 \mathrm{~Sv}$. The interannual variability evident in Fig. 15 (both runs) is most likely driven by changes in wind forcing (identical in both model runs). We infer that an indirect impact of the strongest freshening off the west coast of Greenland is a small component of anti-cyclonic round-Greenland flow, opposing the cyclonic wind-driven circulation and associated southward flow through the Canadian Archipelago.

Direct evidence of an anomalous anti-cyclonic component in round-Greenland flow is provided in Fig. 16, which shows differences (sensitivity minus control) in the zonal and meridional component (upper and lower panels respectively) of depth-averaged currents in 1995 and 2001 (left and right panels respectively). Predominantly positive (northward) anomalies in the meridional component, of around $1 \mathrm{~cm} \mathrm{~s}^{-1}$ are located along the west coast, while similar negative (southward) anomalies lie off the east coast. Corresponding positive (eastward) and negative (westward) anomalies in the zonal component are located in particular along the north coast and around Cape Farewell respectively. Anomalies are generally larger in 2001, compared to 1995 , consistent with the continuing build-up of a fresh anomaly around Greenland. While these depth-averaged current anomalies are of a magnitude consistent with the slopes in SSH anomaly (Fig. 14c), the detailed pattern in Fig. 16 indicates a role for a higher-order effect such as JEBAR. 

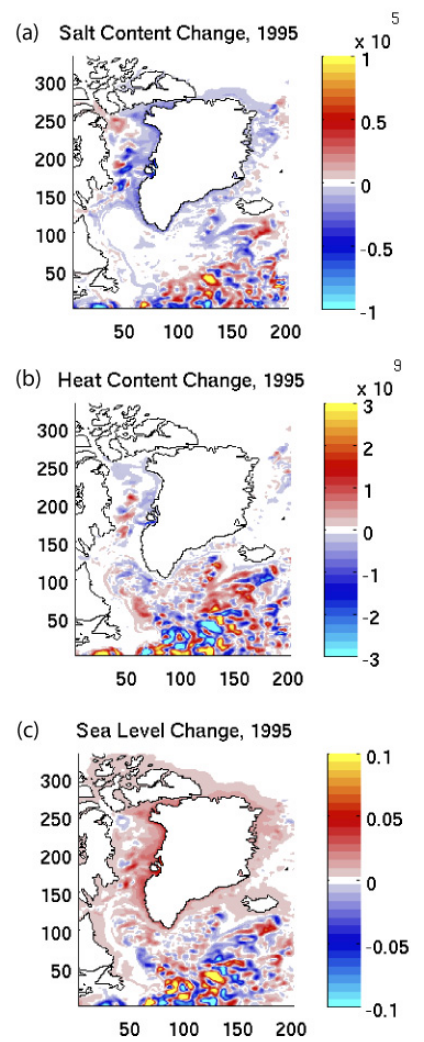
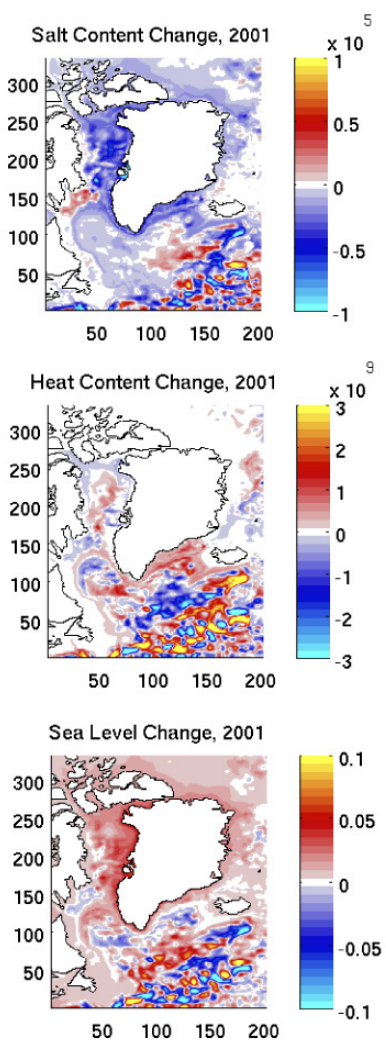

Fig. 14. Annual-mean differences ("sensitivity minus control"), in 1995 and 2001: (a) Full-depth Salt Content $\left(\mathrm{kg} \mathrm{m}^{-3}\right)$; (b) Fulldepth Heat Content $\left(\mathrm{J} \mathrm{m}^{-2}\right)$; (c) Sea Surface Height (m).

\section{Discussion}

The main conclusions drawn from this study are as follows:

1. Over a timescale of 6 months, strong inputs of freshwater from southwest Greenland initially remain within $100-200 \mathrm{~km}$ of the coast

2. Over a timescale of eight years, an anomalous fresh signal can be traced along the narrow boundary current of the Labrador Sea, but the majority of additional freshwater added over 1993-2001 accumulates in Baffin Bay

3. Comparisons of imposed and actual freshwater content anomaly indicate that net freshening amounts to $\sim 15 \%$ of the imposed freshening, due to strong surface salinity damping in the model used here

4. As a consequence of (2), relatively little additional freshwater reaches the interior of the subpolar gyre, and impacts on mixed layer depth and convection are limited

5. On the short timescale considered here, and under modest additional freshwater forcing, the impact on largescale circulation is almost indiscernible, although strong

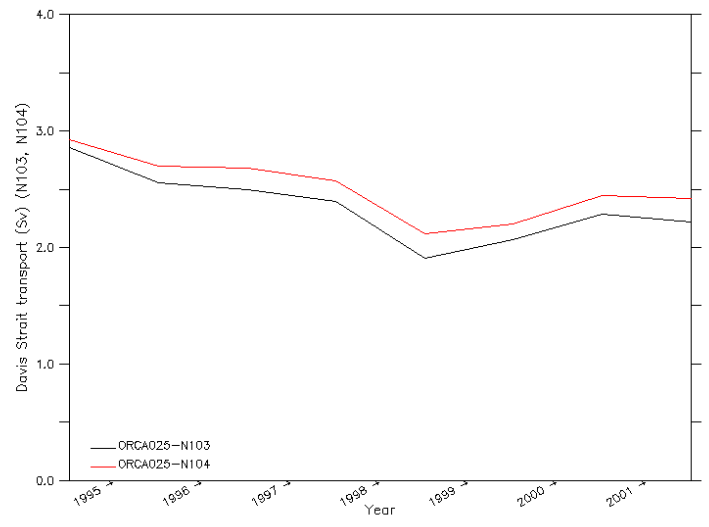

Fig. 15. Annual-mean southward volume transport in Davis Strait (Sv, positive southward) over 1995-2001, in control experiment (red curve) and sensitivity experiment (black curve).

freshening along the west coast of Greenland leads to reduction by $\sim 10 \%$ in the cyclonic flow around Greenland (and associated Arctic export west of Greenland)

While large-scale impacts are minimal, we have considered the indirect effects. Freshening of the Labrador Sea cannot be attributed to the very minor changes in large-scale freshwater transport associated with the gyre circulation (not shown). The majority of surface freshening in the Labrador Sea is due to Greenland freshwater flux (after relaxation), although some changes of surface salinity along the western rim are most likely linked to changes in the seasonal mixed layer cycle. Although not the focus of this study, the meridional overturning circulation may eventually respond to enhanced Greenland freshwater flux, as prescribed in the sensitivity experiment, on longer (multi-decadal) timescales.

The sensitivity experiment undertaken here differs considerably from previous studies in both the location and magnitude of freshwater fluxes applied to the ocean, in addition to the eddy-permitting resolution of the model that is crucially important for resolving the coastal currents that transport additional freshwater. We prescribe month-by-month Greenland mass loss by coastal location, as predicted for the 1990s. This is largely a climatological influx of runoff and calved ice (a loss nearly in balance with accumulation of snow), as opposed to the anomalous runoff/calving specified in other studies, which is concentrated around southern Greenland (Saenko et al., 2007; Stammer, 2008). By adding Greenland freshwater fluxes with realistic geographical distribution and seasonality, we implicitly simulate the oceanic response to a sudden and spatially/temporally uniform amplification of ice sheet melting and discharge, rather than localized or gradual changes in freshwater flux. While the present experiment is based around a hindcast of the 1990s, it is not designed to be representative of actual changes in Greenland freshwater flux during that decade. Our prescribed freshwater influx is also more modest in magnitude and duration, 

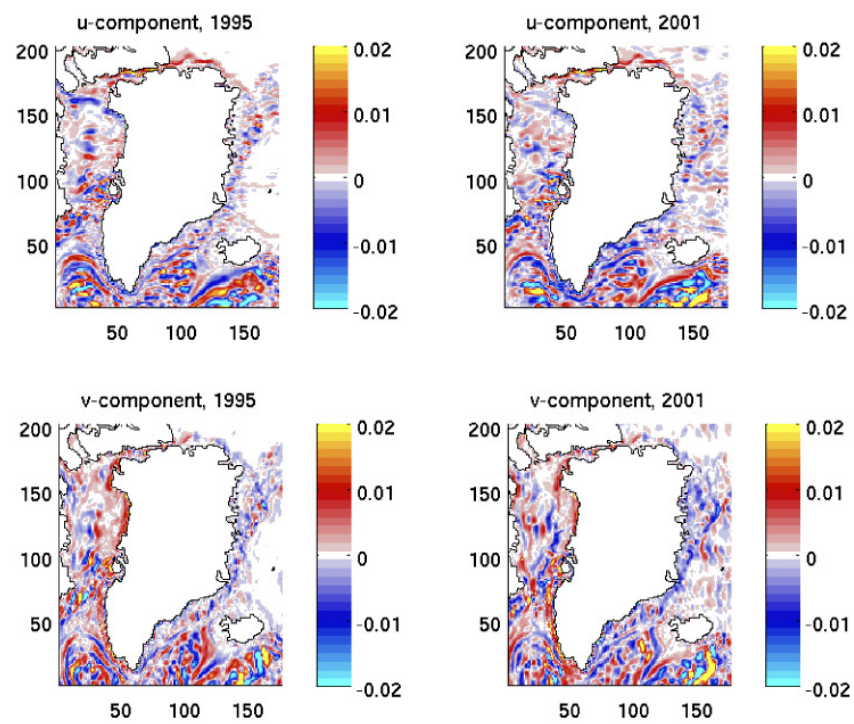

Fig. 16. Differences (sensitivity minus control) in the zonal and meridional component (upper and lower panels respectively) of depth-averaged currents $\left(\mathrm{m} \mathrm{s}^{-1}\right)$, in 1995 and 2001 (left and right panels respectively). Anomalies of the zonal component are positive eastwards. Anomalies of the meridional component are positive northwards.

compared to previous studies. Saenko et al. (2007) specify a total influx of $1 \mathrm{~Sv}$, sustained over 50-100 years, while Stammer (2008) applies constant fluxes of up to $1000 \mathrm{~m}^{3} \mathrm{~s}^{-1}$ (i.e., up to $\sim 30 \mathrm{~km}^{3}$ year $^{-1}$ ), for 50 years. In both cases, the additional fluxes are applied across $\sim 1^{\circ}$ gridcells, extending the influence of more substantial freshwater fluxes further away from the coast of Greenland.

The extent to which a fresh anomaly builds up year on year depends in part on the efficiency with which the surface anomaly is mixed vertically into the water column, while anomalies remaining at the surface are strongly damped in the vicinity of sea ice. The effect of damping is therefore to substantially reduce the prescribed influx of $658 \mathrm{~km}^{3}$ year -1 . Over 1993-2001, freshwater is actually gained at a much lower rate of around $100 \mathrm{~km}^{3}$ year ${ }^{-1}$, which is close to recent estimates for the enhanced rate of Greenland mass loss (Box et al., 2004; Velicogna and Wahr, 2006; IPCC, 2007). The experiment hence serves as a useful guide to the pathways of the additional freshwater entering the boundary currents around Greenland during and since the 1990s.

Given the dominance of freshwater accumulation in Baffin Bay, we consider observational evidence for regional freshening that may be a signature of GrIS melting. Hydrographic observations in Baffin Bay are relatively sparse. Although such observations are sufficient to discern long-term warming and freshening (Zweng and Münchow, 2006), little information is available on recent salinity changes. We note, however, that the strongest long-term freshening has occurred in the upper $250 \mathrm{~m}$ on the west Greenland and Baffin Island shelf breaks (see Figs. 8 and 9 in Zweng and Münchow, 2006). While these trends may be associated with changes in the transport and properties of waters exchanged with the Arctic and the Labrador Sea, our simulation supports an alternative possibility that GrIS meltwater may contribute to the freshening in these locations. With little knowledge of GrIS changes prior to 1990 , it is not possible to further substantiate this. As simulated here, the relatively weak signal of Greenland melting in local boundary currents will be difficult to detect from hydrographic data. While it is now possible to identify Greenland melt water in hydrographic measurements in sections running up to the Greenland coast, signals of change are still within the errors and uncertainties inherent in such a freshwater budget (Sutherland and Pickart, 2008).

An intriguing result is that the additional melting of Greenland has impacted on the primarily wind-driven cyclonic circulation around Greenland (Joyce and Proshutinsky, 2007). In the present experiment, the additional runoff lowers salinity throughout the water column around Greenland, which raises sea surface height $(\mathrm{SSH})$ by $\sim 2 \mathrm{~cm}$ due to the steric effect of freshening and we detect a small anti-cyclonic component of the circulation that reduces the round-island flow by $\sim 10 \%$. This effect should be included alongside the direct effect of mass-flux on SSH and round-island flow, which is not included in NEMO. For completeness, we estimate here the latter effect. Taking a mean annual influx of $0.01 \mathrm{~Sv}$ (annual addition of $3.15 \times 10^{11} \mathrm{~m}^{3}$ ), spread over an average $200 \mathrm{~km}$ of shelf extending from the coast of Greenland (coastline length $\sim 40000 \mathrm{~km}$, hence shelf area $8 \times 10^{12} \mathrm{~m}^{2}$ ), sea level would be raised by $\sim 4 \mathrm{~cm}$. This is additional to (in the same sense as) the steric effect on SSH, so assuming a similar, additional, dynamic response, the round-island flow would be reduced by a further $20 \%$. As a consequence, the southward flow west of Greenland may in total be reduced by around a third.

Whether melting-related changes in flow west of Greenland can be detected will depend on the extent to which we can account for the larger variability due to changes of wind forcing associated with the Arctic Oscillation in particular (Joyce and Proshutinsky, 2007). Nevertheless, enhanced GrIS mass loss in recent years may account for changes that are already observed. Curry et al. (2010) compared transports in Davis Strait (excluding the West Greenland shelf due to the absence of measurements) estimated from current meter data, and detected a decrease of the southward flow from $3.4 \mathrm{~Sv}$ in $1987-90$ to $2.7 \mathrm{~Sv}$ in $2004-05$. They stated that the change is marginally statistically significant but "nonetheless intriguing and contrary to expectations". This observed decrease is consistent with an anomalous anti-cyclonic flow around Greenland, in response to increased GrIS melting over the intervening period.

Non-eustatic changes in sea level occur when ice sheets melt due, primarily, to changes in the gravity field (Mitrovica et al., 2001). These changes result in a lowering in the near field of the ice sheet and rise in the far field. Attempts 
have been made to use this pattern of sea level changes as a "fingerprint" for the contribution of different ice masses to sea level (Mitrovica et al., 2001). The effect of freshwater fluxes on ocean dynamics may, however, be the dominant signal on sea level rather than the gravity (Stammer, 2008). Here, we also find that the short-term local effect on sea level clearly exceeds the larger-scale gravitational effects. After 8 years, the SSH anomaly (Fig. 14c) lies in the range $\pm 5 \mathrm{~cm}$ in the Labrador and Irminger Seas, with large variability at the scale of eddies. For comparison, the implied net freshwater gain in NEMO of $100 \mathrm{~km}^{3}$ year ${ }^{-1}$ is equivalent to an eustatic rise in global sea level of $0.3 \mathrm{~mm}_{\text {year }}{ }^{-1}$. From an observational perspective, a steric sea-level signal of even $2-4 \mathrm{~cm}$ would be hard to detect with satellite altimeters, particularly as the strongest signal lies adjacent to the coast, where altimetric signals are compromised.

In summary, we have forced a state-of-the-art eddypermitting global ocean model with realistic freshwater fluxes from the Greenland ice sheet. The freshwater fluxes are in turn obtained by forcing a mass balance ice sheet model for the period 1991-2000. The ocean model is forced with the 1991-2000 monthly-mean fluxes from summer 1993 onwards, and the simulated freshening thereafter is evident by comparison with a control experiment in which no additional freshwater forcing is imposed. Implicit in this experimental approach is the simple assumption that freshwater input from the Greenland ice sheet can change in one year and thereafter remain constant. While our design is admittedly somewhat idealized, the experiment is a first step towards understanding the fate of additional Greenland melt water and ice in the presence of narrow boundary currents and eddies. Only at sufficiently high resolution are these features explicitly resolved. However, the very narrow (width scale $30 \mathrm{~km}$ ) East Greenland Coastal Current, considered to act as a conduit for Greenland melt water along the east coast (Bacon et al., 2002; Sutherland and Pickart, 2008), is not well resolved in the $1 / 4^{\circ}$ version of NEMO used in the present study.

The experiment provides a basis for further studies. With an improving knowledge of recent changes in the Greenland mass loss, and more up-to-date boundary conditions for forcing NEMO through these more recent years, we can soon extend new experiments to investigate the extent to which actual changes in the ice sheet are freshening the ocean and seas around Greenland. Further prospects include explicit representation of the iceberg flux and along-trajectory melting (Bigg et al., 1997; Levine and Bigg, 2008; Jongma et al., 2009). An outstanding challenge is the representation of non-hydrostatic effects associated with the substantial mass influx, and hence the full implications for barotropic flow around Greenland and Arctic export through the Canadian Archipelago.
Acknowledgements. This study was originally undertaken as an MSc project at the University of Southampton by D. Desbruyères. The development, use and analysis of NEMO are funded through the "Oceans 2025" Strategic Research Programme of the UK Natural Environment Research Council (NERC), which also supports the research of Andrew Coward, Beverly de Cuevas and Yevgeny Aksenov. JLB was funded by UK NERC grants NER/T/S/2002/00462 and NE/C509474/1. We thank two anonymous reviewers for several helpful comments.

Edited by: M. Hecht

\section{References}

Bacon, S., Reverdin, G., Rigor, I. G., and Snaith, H. M.: A freshwater jet on the east Greenland Shelf, J. Geophys. Res., 107(C7), 1-5, doi:10.1029/2001JC000935, 2002.

Bigg, G. R., Wadley, M. R., Stevens, D. P., and Johnson, J. A.: Modelling the dynamics and thermodynamics of icebergs, Cold Regions Sci. Technol., 26, 113-135, 1997.

Bougamont, M., Bamber J. L., and Greuell, W.: A surface mass balance model for the Greenland Ice Sheet, J. Geophys. Res., 110, F04018, doi:10.1029/2005JF000348, 2005.

Bourke, R. H., Newton, J. L., Paquette, R. G., and Tunnicliffe, M. D.: Circulation and water masses of the East Greenland Shelf, J. Geophys. Res., 92, 6729-6740, 1987.

Box, J. E., Bromwich, D. H., and Bai, L.-S.: Greenland ice sheet surface mass balance 1991-2000: Application of Polar MM5 mesoscale model and in situ data, J. Geophys. Res., 109, D16105, doi:10.1029/2003JD004451, 2004.

Budéus, G., Schneider, W., and Kattner, G.: Distribution and exchange of water masses in the Northeast Water Polynya (Greenland Sea), J. Mar. Syst., 10, 123-138, 1997.

Campin, J. M., Marshall, J., and Ferreira, D.: Sea-ice ocean coupling using a rescaled vertical coordinate $\mathrm{z}^{*}$, Ocean Model., 24, 1-14, 2008.

Cuny, J., Rhines, P. B., Niiler, P. P., and Bacon, S.: Labrador Sea boundary currents and the fate of the Irminger Sea Water, J. of Phys. Ocean., 32, 627-647, 2002.

Curry, B., Lee, C. M., and Petrie, B.: Volume, freshwater and heat fluxes through Davis Strait, 2004-2005, submitted to J. Phys. Oceanogr., 2010.

Fettweis, X.: Reconstruction of the 1979-2006 Greenland ice sheet surface mass balance using the regional climate model MAR, The Cryosphere, 1, 21-40, 2007, http://www.the-cryosphere-discuss.net/1/21/2007/.

Godfrey, J. S.: A Sverdrup model of the depth-integrated flow from the world ocean allowing for island circulations, Geophys. Astrophys. Fluid Dyn., 45, 89-112, 1989.

Grist, J. P., Josey, S. A., Marsh, R., Good, S., Coward, A. C., deCuevas, B. A., Alderson, S. G., New, A. L., and Madec, G.: The Roles of Surface Heat Flux and Ocean Heat Transport During Four Decades of Atlantic Ocean Temperature Variability, Ocean Dynam., 61, doi:10.1007/s10236-010-0292-4, 2010.

Holliday, N. P., Bacon, S., Allen, J., and McDonagh, E. L.: Circulation and Transport in the Western Boundary Currents at Cape Farewell, Greenland, J. Phys. Oceanogr., 39, 1854-1870, 2009. 
Hughes, C. W., and Meredith, M. P.: Coherent sea-level fluctuations along the global continental slope, Phil. Trans. Roy. Soc. Lond. A, 364, 885-901, 2006.

Huthnance, J. M.: Slope currents and “JEBAR”, J. Phys. Oceanogr., 14, 795-810, 1984.

IPCC (2007): WG1 AR4 Report, Chapter 4, "Observations: Changes in Snow, Ice and Frozen Ground", Section 4.6, "Changes and Stability of Ice Sheets and Ice Shelves"

Jongma, J. I., Driesschaert, E., Fichefet, T., Goosse, H., and Renssen, H.: Facilitation of Southern Ocean sea ice formation in a three dimensional climate model with interactively coupled icebergs, Ocean Model., 104-113, doi:10.1016/j.ocemod.2008.09.007, 2009.

Joyce, T. M. and Proshutinsky, A.: Greenland's Island Rule and the Arctic Ocean circulation, J. Mar. Res., 65, 639-653, 2007.

Lazier, J. R. N. and Wright, D. G.: Annual velocity variations in the Labrador Current, J. Phys. Oceanogr., 23, 659-678, 1993.

Levine, R. C. and Bigg, G. R.: Sensitivity of the glacial ocean to Heinrich events from different iceberg sources, as modeled by a coupled atmosphere-iceberg-ocean model, Paleoceanography, 23, PA4213, doi:10.1029/2008PA001613, 2008.

Lique, C., Treguier, A. M., Scheinert, M., and Penduff, T.: A modelbased study of ice and freshwater transport variability along both sides of Greenland, Clim. Dyn., 33, 685-705, 2009.

Melling, H.: Sea ice of the northern Canadian Arctic Archipelago, J. Geophys. Res., 107(C11), 3181, doi:10.1029/ 2001JC001102, 2002

Melling, H., Agnew, T. A., Falkner, K. K., Greenberg, D. A., Lee, C. M., Münchow, A., Petrie, B., Prinsenberg, S. J., Samelson, R. M., and Woodgate, R. A.: Fresh-water fluxes via Pacific and Arctic Outflow across the Canadian Polar Shelf, in: Arctic-Subarctic Ocean Fluxes: Defining the Role of the Northern Seas in Climate, edited by: Dickson, R. R., Meincke, J., and Rhines, P., Springer Verlag, The Netherlands, 193-248, 2008.

Mitrovica, J. X., Tamisiea, M. E., Davis, J. L., and Milne, G. A.: Recent mass balance of polar ice sheets inferred from patterns of global sea-level change, Nature, 409(6823), 1026-1029, 2001.

National Snow and Ice Data Center: Arctic Sea Ice New \& Analysis, see http://nsidc.org/arcticseaicenews/2010/040610. html, 2010.

Pickart, R. S., Torres, D. J., and Clarke, R. A.: Hydrography of the Labrador Sea during active convection, J. Phys. Oceanogr., 32, 428-457, 2002.
Rabe, B., Schauer, U., Mackensen, A., Karcher, M., Hansen, E., and Beszczynska-Móller, A.: Freshwater components and transports in the Fram Strait recent observations and changes since the late 1990s, Ocean Sci., 5, 219-233, doi:10.5194/os-5-2192009, 2009.

Rignot, E. and Kanagaratnam, P.: Changes in the Velocity Structure of the Greenland Ice Sheet, Science, 311(5763), 986-990, 2006.

Saenko, O. A., Weaver, A. J., Robitaille, D. Y., and Flato, G. M.: Warming of the subpolar Atlantic triggered by freshwater discharge at the continental boundary, Geophys. Res. Lett., 34, L15604, doi:10.1029/2007GL030674, 2007.

Schauer, U., Beszczynska-Möller, A., Walczowski, W., Fahrbach, E., Piechura, J., and Hansen, E.: Variation of measured heat flow through the Fram Strait between 1997 and 2006. ArcticSubarctic Ocean Fluxes: Defining the Role of the Northern Seas in Climate; edited by: Dickson, R. R., Meincke, J., and Rhines, P., Springer Verlag, Netherlands, pp. 65-86, 2008.

Stammer, D.: Response of the global ocean to Greenland and Antarctic ice melting, J. Geophys. Res., 113, C06022, doi:10.1029/2006JC004079, 2008.

Sutherland, D. and Pickart, R. S.: The East Greenland Coastal Current: Structure, variability, and forcing, Prog. Oceanogr., 78, 5877, 2008

Vancoppenolle, M., Fichefet, T., Goosse, H., Bouillon, S., Madec, G., and Morales Maqueda, M. A.: Simulating the mass balance and salinity of Arctic and Antarctic sea ice. 1. Model description and validation, Ocean Model., 27, 33-53, doi:10.1016/j.ocemod.2008.10.005, 2009.

van den Broeke, M., Bamber, J. L., Ettema, J., Rignot, E., Schrama E. J. O., van de Berg, W., van Meijgaard, E., Velicogna, I., and Wouters, B.: Partitioning recent Greenland mass loss, Science, 326(5955), 984-986, 2009.

Velicogna, I. and Wahr, J.: Acceleration of Greenland ice mass loss in spring 2004, Nature, 443, 329-331, 2006.

Velicogna I.: Increasing rates of ice mass loss from the Greenland and Antarctic ice sheets revealed by GRACE, Geophys. Res. Lett., 36, L19503, doi:10.1029/2009GL040222, 2009.

Zweng, M. M. and Münchow, A.: Warming and freshening of Baffin Bay, J. Geophys. Res., 111, 1916-2003, C07016, doi:10.1029/2005JC003093, 2006. 